\title{
Pharmacokinetic study of aldoxorubicin in patients with solid tumors
}

\author{
Monica M. Mita • Ronald B. Natale • Edward M. Wolin • \\ Brenda Laabs • Hillary Dinh • Scott Wieland • \\ Daniel J. Levitt • Alain C. Mita
}

Received: 1 October 2014 / Accepted: 3 November 2014 / Published online: 12 November 2014

(C) Springer Science+Business Media New York 2014

Summary Introduction Aldoxorubicin, a prodrug of doxorubicin, binds covalently to serum albumin in the bloodstream and accumulates in tumors. Aldoxorubicin can be administered at doses several-fold higher than doxorubicin can, without associated acute cardiotoxicity. Purpose This study fully evaluated the pharmacokinetic profile of aldoxorubicin (serum and urine). Methods Eighteen patients with advanced solid tumors received aldoxorubicin 230 or $350 \mathrm{mg} / \mathrm{m}^{2}$ (equivalent in drug load to doxorubicin at doses of 170 or $260 \mathrm{mg} / \mathrm{m}^{2}$, respectively) once every 21 days. Blood samples were taken in cycle 1 before aldoxorubicin infusion, and at 5 , 15,30 , and $60 \mathrm{~min}$, and at 2, 4, 8, 12, 16, 24, 48, and $72 \mathrm{~h}$ after infusion. Urine samples were taken in cycle 1 at 24, 48, and $72 \mathrm{~h}$ after infusion. Limited blood sampling was done in cycle 3 , before aldoxorubicin infusion, and at $60 \mathrm{~min}$ and at 2, 4, and $8 \mathrm{~h}$ after infusion. Results The long mean half-life (20.1$21.1 \mathrm{~h}$ ), narrow mean volume of distribution $(3.96-4.08 \mathrm{~L} /$ $\left.\mathrm{m}^{2}\right)$, and slow mean clearance rate $\left(0.136-0.152 \mathrm{~L} / \mathrm{h} / \mathrm{m}^{2}\right)$ suggest that aldoxorubicin is stable in circulation and does not accumulate readily in body compartments outside of the bloodstream. Very little doxorubicin and its major metabolite doxorubicinol, which has been implicated in doxorubicinassociated cardiotoxicity, are excreted in urine. This might explain the lack of cardiotoxicity observed thus far with aldoxorubicin. Conclusions Our findings support dosing and administration schemas used in an ongoing phase 3 clinical

M. M. Mita $(\bowtie) \cdot$ R. B. Natale $\cdot$ E. M. Wolin $\cdot$ B. Laabs $\cdot$ A. C. Mita Samuel Oschin Comprehensive Cancer Institute, Cedars-Sinai Medical Center, 8700 Beverly Boulevard, Suite MS31, Los Angeles, CA 90048 , USA

e-mail: monica.mita@cshs.org

H. Dinh · S. Wieland · D. J. Levitt

CytRx Corporation, 11726 San Vicente Boulevard, Suite 650, Los Angeles, CA 90049, USA study of aldoxorubicin in soft tissue sarcoma, and phase 2 clinical studies in small cell lung cancer, glioblastoma, and Kaposi's sarcoma.

Keywords Doxorubicin · Doxorubicinol · Pharmacokinetics $\cdot$ Prodrugs $\cdot$ Serum albumin

\section{Introduction}

Doxorubicin is approved, either alone or in combination with other drugs, for treatment of numerous cancers [1,2]. Unfortunately, the benefits of doxorubicin-based regimens are diminished by dose-dependent, drug-related toxicities, particularly cardiotoxicity $[3,4]$. Early research suggested that the cardiotoxicity of doxorubicin could be attributable to metabolism of doxorubicin to doxorubicinol and the subsequent action of doxorubicinol on cardiac tissue [5,6]. As a result, dose-intensive or long-term treatment with doxorubicin exceeding a cumulative dose of $550 \mathrm{mg} / \mathrm{m}^{2}$ is not recommended.

Aldoxorubicin is a prodrug of doxorubicin that is derivatized at its $\mathrm{C}$-13-keto position and is conjugated to a linker consisting of an acid-sensitive hydrazine moiety, a 6carbon spacer, and a thiol-binding maleimide (6maleimidocaproic acid hydrazide) [7]. When aldoxorubicin enters the bloodstream, this linker molecule binds rapidly (within $5 \mathrm{~min}$ ) and covalently to the cysteine-34 amino acid of endogenous albumin [7]. Due to the enhanced vascular permeability and poor lymphatic drainage that are characteristic of tumors (enhanced permeability and retention) [8], albumin-bound doxorubicin accumulates in the tumor and is then released in the acidic environment of the tumor or inside tumor cells via cleavage of the acid-sensitive hydrazine bond between the drug and the linker [7]. 
In a preliminary phase 1 study of aldoxorubicin in patients with advanced solid tumors, dose-limiting toxicities of mucositis and neutropenia were observed at $460 \mathrm{mg} / \mathrm{m}^{2}$ (equivalent in drug load to doxorubicin $340 \mathrm{mg} / \mathrm{m}^{2}$ ) [9]. The dose recommended for further study was $350 \mathrm{mg} / \mathrm{m}^{2}$ (equivalent to doxorubicin $260 \mathrm{mg} / \mathrm{m}^{2}$ ) [9]. No clinical signs of cardiotoxicity were observed on study or during the follow-up period, even among patients treated at the higher dose levels and/or for extended periods [9]. The biological basis for the lack of cardiotoxicity associated with aldoxorubicin treatment is unknown. The amount of doxorubicinol generated after aldoxorubicin administration has not previously been measured.

Recently, a new formulation of aldoxorubicin was developed that eliminates or reduces the amount of inactive ingredients, improves reconstitution, and allows for drug delivery in a short time period $(30 \mathrm{~min})$. The phase 1 pharmacokinetic study reported herein was conducted to fully evaluate the pharmacokinetic profile in both serum and urine of the new formulation of aldoxorubicin with additional assessment of free doxorubicin and its metabolite, doxorubicinol, in patients with advanced solid tumors.

\section{Methods}

\section{Study design}

This was a phase 1, open-label, single-center, pharmacokinetic study of aldoxorubicin 230 or $350 \mathrm{mg} / \mathrm{m}^{2}$ (equivalent to doxorubicin 170 or $260 \mathrm{mg} / \mathrm{m}^{2}$, respectively) in adult patients with advanced solid tumors that have either relapsed or are refractory to standard therapy (ClinicalTrials.gov registry no. NCT01706835). The primary objective was to evaluate the pharmacokinetic profile of aldoxorubicin in patients with advanced solid tumors. The secondary objective was to evaluate treatment-related toxicities of aldoxorubicin in these patients.

\section{Ethics}

The study protocol was approved by the study site's institutional review board and was conducted in accordance with current US Food and Drug Administration regulations, International Conference on Harmonisation Guideline for Good Clinical Practice, the principles of the Declaration of Helsinki, and other applicable regulations and guidelines. All patients gave signed informed consent before enrollment in the study.

\section{Patients}

Eligible patients were 18 years of age or older, had a histologically or cytologically confirmed malignant solid tumor that had relapsed or was refractory to standard therapy, measurable or evaluable disease, Eastern Cooperative Oncology Group (ECOG) performance status of 0-2, and life expectancy of $>12$ weeks. Prior anthracycline therapy was allowed, with no limitation on cumulative dose. Those who had received prior radiation therapy had stable central nervous system metastasis with no progression of brain metastasis by computed tomography/magnetic resonance imaging scans within 4 weeks of screening. Women of childbearing age were not pregnant or lactating at screening, and used adequate birth control methods during the study.

Patients were excluded if they had palliative surgery, chemotherapy, immunotherapy, and/or radiation treatment within 4 weeks of screening; exposure to any investigational agent within 30 days of screening; laboratory values at screening that indicated impairment of liver function or bone marrow function; clinically evident congestive heart failure (New York Heart Association functional class II or higher); serious, clinically significant cardiac arrhythmia or recent history (within 6 months of screening) or active coronary artery disease with or without angina pectoris; serious myocardial dysfunction; history of human immunodeficiency viral infection or active, clinically significant serious infection requiring medical treatment; or major surgery within 4 weeks of study drug treatment.

Treatments, assessments, technical methods

Aldoxorubicin 230 or $350 \mathrm{mg} / \mathrm{m}^{2}$ was administered as a 30-min intravenous infusion on day 1 of each 21-day cycle. The use of granulocyte colony stimulating factor (GCSF) was allowed at the discretion of the investigator and according to the American Society of Clinical Oncology guidelines [10]. Blood samples for pharmacokinetic analyses were taken immediately before the start of the aldoxorubicin infusion, and then at 5, 15, 30, and $60 \mathrm{~min}$, and at 2, 4, 8, 12, 16, 24, 48, and $72 \mathrm{~h}$ after the start of the infusion in cycle 1 . Blood samples for limited pharmacokinetic analyses were taken before aldoxorubicin administration, and then at $60 \mathrm{~min}$ and at 2, 4, and $8 \mathrm{~h}$ after the start of the infusion in cycle 3 . Serum concentrations of albumin-bound doxorubicin, unbound (or free) doxorubicin, and doxorubicinol were determined by highperformance liquid chromatography tandem mass spectrometry for each sample. Urine samples were taken at 24,48 , and $72 \mathrm{~h}$ after the start of the infusion in cycle 1 . The amount of doxorubicin and doxorubicinol excreted in urine and renal clearance was determined.

Adverse events were assessed at each scheduled clinic visit, at which time the incidence, severity, duration, causality, seriousness, and types of adverse events, as well as changes in physical examination, vital signs, and clinical laboratory results were documented. Cardiac function was assessed by 
echocardiography or multigated acquisition scan on days 28 and 85 , at study end or early termination, and every 2 months thereafter.

\section{Sample size}

Eighteen patients were enrolled into this study at a single center in the US.

\section{Statistics}

All patients who entered active treatment and received at least one dose of aldoxorubicin and had complete pharmacokinetic sampling were included in the pharmacokinetic analyses. Descriptive statistics (mean, minimum, median, maximum, standard deviations, and coefficient of variance) for the plasma concentrations, and plasma and urine pharmacokinetic parameters were calculated for both doses.

All patients who entered active treatment and received at least one dose of aldoxorubicin were included in the safety analyses. Safety data were summarized using descriptive statistics.

\section{Results}

Between October 2012 and September 2013, 18 patients were enrolled. All 18 patients were included in the safety analysis and in the pharmacokinetics analyses of cycle 1: 11 patients in the $230 \mathrm{mg} / \mathrm{m}^{2}$ cohort and 7 in the $350 \mathrm{mg} / \mathrm{m}^{2}$ cohort. Eleven patients were included in the pharmacokinetics analyses of cycle 3: 6 patients in the $230 \mathrm{mg} / \mathrm{m}^{2}$ cohort and 5 in the $350 \mathrm{mg} / \mathrm{m}^{2}$ cohort.

Baseline patient demographics and disease characteristics are summarized in Table 1. Median age of the study population was 61.7 years. Most patients $(83.3 \%)$ were Caucasian, and most $(88.9 \%)$ had ECOG performance status of 0 or 1 . The most common primary tumor site was the lung, which was diagnosed in $44.4 \%$ of patients. Patients in the $230 \mathrm{mg} /$ $\mathrm{m}^{2}$ and the $350 \mathrm{mg} / \mathrm{m}^{2}$ cohorts had a median of 2 and 4 prior chemotherapy regimens, respectively.

Results of the cycle 1 pharmacokinetic analyses are summarized in Table 2. Mean plasma concentrations over time after aldoxorubicin infusion for each dose group are shown in Fig. 1. Following a single dose of aldoxorubicin on day 1 of cycle 1 , peak plasma concentrations $\left(\mathrm{C}_{\max }\right)$ of aldoxorubicin were reached at a median of $0.75 \mathrm{~h}\left(230 \mathrm{mg} / \mathrm{m}^{2}\right)$ and $1.00 \mathrm{~h}$ $\left(350 \mathrm{mg} / \mathrm{m}^{2}\right)$ after the start of aldoxorubicin infusion $\left(\mathrm{t}_{\max }\right)$. The $t_{\max }$ of doxorubicin was $0.58 \mathrm{~h}\left(230 \mathrm{mg} / \mathrm{m}^{2}\right)$ and $0.68 \mathrm{~h}$ $\left(350 \mathrm{mg} / \mathrm{m}^{2}\right)$. The $t_{\max }$ for doxorubicinol was much longer, a median of $36.5 \mathrm{~h}\left(230 \mathrm{mg} / \mathrm{m}^{2}\right)$ and $48.5 \mathrm{~h}\left(350 \mathrm{mg} / \mathrm{m}^{2}\right)$. The plasma concentration of aldoxorubicin was greater than that of doxorubicin by about 40-to 300 -fold, depending on the individual. The plasma concentration of doxorubicinol, the main metabolite of doxorubicin, was very near the limit of detection.

Both $\mathrm{C}_{\max }$ and the area under the plasma doxorubicin concentration-time curve from time 0 to infinity $\left(\mathrm{AUC}_{0-\infty}\right)$ of aldoxorubicin and doxorubicin were higher with the $350 \mathrm{mg} / \mathrm{m}^{2}$ dose of aldoxorubicin than the $230 \mathrm{mg} / \mathrm{m}^{2}$ dose, but systemic clearance (CL) and volume of distribution at steady state $\left(\mathrm{V}_{\mathrm{ss}}\right)$ of aldoxorubicin, and apparent systemic clearance $(\mathrm{CL} / \mathrm{F})$ and apparent volume of distribution $\left(\mathrm{V}_{\mathrm{d}} / \mathrm{F}\right)$ of doxorubicin were similar between aldoxorubicin doses. Importantly, both the $\mathrm{C}_{\max }$ and $\mathrm{AUC}_{0-\infty}$ of free doxorubicin represented a small fraction of the $\mathrm{C}_{\max }$ and $\mathrm{AUC}_{0-\infty}$, respectively, of albumin-bound doxorubicin. The $\mathrm{C}_{\max }$ of doxorubicinol was also higher with the $350 \mathrm{mg} / \mathrm{m}^{2}$ aldoxorubicin dose, but overall plasma concentration of doxorubicinol, as an absolute quantity and as a fraction of free doxorubicin, was very low. The $\mathrm{AUC}_{0-\infty}$ of doxorubicinol could not be calculated.

The harmonic mean \pm pseudo-standard deviation half-life $\left(\mathrm{t}_{1 / 2}\right)$ values for aldoxorubicin were similar for the $230 \mathrm{mg} / \mathrm{m}^{2}$ and $350 \mathrm{mg} / \mathrm{m}^{2}$ doses $(20.1 \pm 3.3 \mathrm{~h}$ vs $21.1 \pm 3.4 \mathrm{~h})$. The $\mathrm{t}_{1 / 2}$ values for doxorubicin were higher with the $350 \mathrm{mg} / \mathrm{m}^{2}$ dose of aldoxorubicin than with the $230 \mathrm{mg} / \mathrm{m}^{2}$ dose.

There were no apparent differences in pharmacokinetic parameters between cycle 1 and cycle 3 (Fig. 2). There was no evidence of accumulation of aldoxorubicin over multiple cycles of administration.

Urine levels of doxorubicin and doxorubicinol over time are summarized in Table 3. Overall, urine levels of doxorubicinol were very low, relative to levels of free doxorubicin.

Adverse events occurring on study are summarized in Table 4 . Of the 22 grade 3 or 4 adverse events reported, 11 $(50.0 \%)$ were deemed possibly or definitely related to study drug. One aldoxorubicin-related serious adverse event, febrile neutropenia, was reported; this patient did not receive GCSF following the occurrence of this event. Two deaths from tumor progression occurred. Although 10 (55.6\%) patients experienced $>5 \%$ prolongation of QTc from baseline, none of these events was considered clinically significant. Four $(22.2 \%)$ patients, three in the $230-\mathrm{mg} / \mathrm{m}^{2}$ dose group and one in the $350-\mathrm{mg} / \mathrm{m}^{2}$ dose group, had QTc prolongation $\geq 470 \mathrm{~ms}$, but none of these events was considered clinically significant. One patient who entered the study with QTc $>470 \mathrm{~ms}$ had fluctuations in QTc during treatment that stabilized to near baseline value post-treatment. One patient experienced grade 3 tachycardia after 9 cycles; this was not considered a serious adverse event and no specific action was taken. One (5.6\%) patient, in the $230-\mathrm{mg} / \mathrm{m}^{2}$ dose group, had a decrease in left ventricular ejection fraction from baseline of at least $10 \%$, but this was not considered clinically significant. Overall, there 
Table 1 Baseline patient characteristics and disease characteristics $(N=18)$

\begin{tabular}{|c|c|c|c|}
\hline \multirow[t]{2}{*}{ Parameter } & \multicolumn{3}{|c|}{ Aldoxorubicin dose group } \\
\hline & $230 \mathrm{mg} / \mathrm{m}^{2}$ & $350 \mathrm{mg} / \mathrm{m}^{2}$ & All patients \\
\hline No. of patients & 11 & 7 & 18 \\
\hline Median age (range), years & $64.0(34.0-75.9)$ & $57.9(37.3-69.4)$ & $61.7(34.0-75.9)$ \\
\hline Male / female, n (\%) & 4 / $7(36.4$ / 63.6) & $4 / 3(57.1 / 42.9)$ & $8 / 10(44.4 / 55.6)$ \\
\hline \multicolumn{4}{|l|}{ Race, n (\%) } \\
\hline Caucasian & $8(72.7)$ & $7(100)$ & $15(83.3)$ \\
\hline Black or African American & $1(9.1)$ & - & $1(5.6)$ \\
\hline Asian & $2(18.2)$ & - & $2(11.1)$ \\
\hline \multicolumn{4}{|l|}{ ECOG performance status, n (\%) } \\
\hline $0-1$ & $9(81.8)$ & $7(100)$ & $16(88.9)$ \\
\hline 2 & $2(18.2)$ & - & $2(11.1)$ \\
\hline \multicolumn{4}{|l|}{ Tumor primary site } \\
\hline Esophagus & $1(9.1)$ & - & $1(5.6)$ \\
\hline Lung & $5(45.5)^{\mathrm{a}}$ & $3(42.9)^{\mathrm{b}}$ & 8 (44.4) \\
\hline Ovary & - & $1(14.3)$ & $1(5.6)$ \\
\hline Pancreas & - & $1(14.3)$ & $1(5.6)$ \\
\hline Soft tissue & - & $1(14.3)$ & $1(5.6)$ \\
\hline Testicle & $1(9.1)$ & - & $1(5.6)$ \\
\hline Thyroid & $1(9.1)$ & - & $1(5.6)$ \\
\hline Urothelium & $1(9.1)$ & - & $1(5.6)$ \\
\hline Unknown $^{\mathrm{c}}$ & $2(18.2)$ & $1(14.3)$ & $3(16.7)$ \\
\hline Median no. of prior chemotherapy regimens (range) & $2(0-5)$ & $4(2-8)$ & $2(0-8)$ \\
\hline
\end{tabular}

ECOG Eastern Cooperative Oncology Group

${ }^{\text {a }}$ Includes one diagnosis of metastatic small-cell lung cancer

${ }^{\mathrm{b}}$ Includes one diagnosis of mesothelioma of the lung and one diagnosis of late-stage small-cell lung cancer

c "Unknown" includes neuroendocrine tumor of unknown or unspecified primary site

was little evidence of acute cardiotoxicity associated with aldoxorubicin treatment.

Six patients had tumor responses or tumor shrinkage on aldoxorubicin during the study. The four patients in the 230$\mathrm{mg} / \mathrm{m}^{2}$ group with tumor response had completed a median of 9 cycles of treatment (range, 7-21), and of the two patients in the $350-\mathrm{mg} / \mathrm{m}^{2}$ group with tumor response, one completed 5 cycles and the other 9 cycles of treatment. Three patients had partial responses (PR) to treatment, including one diagnosed with thyroid cancer with confirmed PR (230-mg/ $\mathrm{m}^{2}$ group) who remained on study for over 6 months ( 9 cycles completed), one diagnosed with mesothelioma with confirmed PR (350- $\mathrm{mg} / \mathrm{m}^{2}$ group) who was withdrawn from the study after 9 cycles because of paroxystical atrial fibrillation, and one diagnosed with small-cell lung cancer (SCLC) with unconfirmed PR after 4 cycles (230-mg/ $\mathrm{m}^{2}$ group) but progressive disease (PD) after 7 cycles. Three patients had stable disease with tumor shrinkage, including one diagnosed with SCLC who remained on study for over 1 year (21 cycles completed; $230-\mathrm{mg} / \mathrm{m}^{2}$ group), one diagnosed with a small-cell neuroendocrine tumor who remains on study at the time of this report (1+ year; $230-\mathrm{mg} / \mathrm{m}^{2}$ group), and one diagnosed with ovarian cancer with tumor shrinkage after 2 cycles (350$\mathrm{mg} / \mathrm{m}^{2}$ group) but PD after 5 cycles.

\section{Discussion}

The pharmacokinetic analyses described in this report show that aldoxorubicin has a mean circulating $t_{1 / 2}$ of 20.1-21.1 h, a narrow mean volume of distribution of $3.96-4.08 \mathrm{~L} / \mathrm{m}^{2}$, and a slow mean clearance rate of $0.136-0.152 \mathrm{~L} / \mathrm{h} / \mathrm{m}^{2}$. These characteristics suggest that aldoxorubicin, either bound or unbound to serum albumin, is stable in circulation and does not accumulate to a substantial degree in body compartments outside of the bloodstream. Furthermore, plasma concentrations of free doxorubicin and doxorubicinol were only small fractions of the plasma concentration of albumin-bound doxorubicin. Therefore, almost all doxorubicin in the circulation 
Table 2 Pharmacokinetic parameters after aldoxorubicin infusion on day 1 of cycle $1(N=18)$

\begin{tabular}{|c|c|c|c|c|c|c|c|}
\hline \multirow[t]{2}{*}{ Parameter } & \multirow[t]{2}{*}{ Statistic } & \multicolumn{2}{|c|}{ Albumin-bound doxorubicin } & \multicolumn{2}{|l|}{ Free doxorubicin } & \multicolumn{2}{|l|}{ Doxorubicinol } \\
\hline & & $\begin{array}{l}230 \mathrm{mg} / \mathrm{m}^{2} \\
(n=11)\end{array}$ & $\begin{array}{l}350 \mathrm{mg} / \mathrm{m}^{2} \\
(n=7)\end{array}$ & $\begin{array}{l}230 \mathrm{mg} / \mathrm{m}^{2} \\
(n=11)\end{array}$ & $\begin{array}{l}350 \mathrm{mg} / \mathrm{m}^{2} \\
(n=7)\end{array}$ & $\begin{array}{l}230 \mathrm{mg} / \mathrm{m}^{2} \\
(n=11)\end{array}$ & $\begin{array}{l}350 \mathrm{mg} / \mathrm{m}^{2} \\
(n=7)\end{array}$ \\
\hline $\mathrm{t}_{\max }, \mathrm{h}$ & $\begin{array}{l}\text { Median } \\
\quad \text { (range) }\end{array}$ & $0.75(0.58-1.5)$ & $1.00(0.583-2.5)$ & $0.58(0.58-1.5)$ & $0.75(0.58-0.75)$ & $36.5^{\mathrm{c}}(12.5-72.5)$ & $48.5(12.5-72.5)$ \\
\hline $\mathrm{C}_{\max }, \mathrm{ng} / \mathrm{mL}$ & Mean (SD) & $67,400(5750)$ & $105,000(23,400)$ & $1,200(974)$ & $2,470(2040)$ & $4.17(6.20)$ & $13.7(10.4)$ \\
\hline$t_{1 / 2}, h$ & $\begin{array}{l}\text { Harmonic mean } \\
\quad \text { (pseudo-SD) }\end{array}$ & $20.1(3.28)$ & $21.1(3.36)$ & $11.5(2.83)$ & $16.0(6.67)$ & $\mathrm{NC}$ & $\mathrm{NC}$ \\
\hline $\begin{array}{l}\mathrm{AUC}_{0-\mathrm{t}}, \\
\mathrm{ng} \cdot \mathrm{h} / \mathrm{mL}\end{array}$ & Mean (SD) & $1,420,000(197,000)$ & $2,490,000(623,000)$ & $6,060(3320)$ & $12,000(5810)$ & $212(310)$ & $661(581)$ \\
\hline $\begin{array}{l}\mathrm{AUC}_{0-\infty}, \\
\mathrm{ng} \cdot \mathrm{h} / \mathrm{mL}\end{array}$ & Mean (SD) & $1,550,000(254,000)$ & $2,760,000(724,000)$ & $8,570(3880)$ & $15,700(7390)$ & $\mathrm{NC}$ & $\mathrm{NC}$ \\
\hline $\mathrm{CL}, \mathrm{L} / \mathrm{h} / \mathrm{m}^{2}$ & Mean (SD) & $0.152(0.0249)$ & $0.136(0.0395)$ & NA & NA & NA & NA \\
\hline $\mathrm{V}_{\mathrm{ss}}, \mathrm{L} / \mathrm{m}^{2}$ & Mean (SD) & $4.08(0.431)$ & $3.96(1.16)$ & NA & NA & NA & NA \\
\hline $\mathrm{CL} / \mathrm{F}^{\mathrm{a}}, \mathrm{L} / \mathrm{h} / \mathrm{m}^{2}$ & Mean (SD) & NA & NA & $23.2(10.5)$ & $20.5(11.2)$ & NA & NA \\
\hline $\mathrm{V}_{\mathrm{d}} / \mathrm{F}^{\mathrm{a}}, \mathrm{L} / \mathrm{m}^{2}$ & Mean (SD) & NA & NA & $391(156)$ & 485 (178) & $\mathrm{NA}$ & NA \\
\hline $\mathrm{CL} / \mathrm{F}^{\mathrm{b}}, \mathrm{L} / \mathrm{h} / \mathrm{m}^{2}$ & Mean (SD) & NA & NA & $32.4(14.6)$ & $27.7(15.1)$ & $\mathrm{NA}$ & NA \\
\hline $\mathrm{V}_{\mathrm{d}} / \mathrm{F}^{\mathrm{b}}, \mathrm{L} / \mathrm{m}^{2}$ & Mean (SD) & NA & NA & $545(217)$ & 653 (239) & $\mathrm{NA}$ & NA \\
\hline
\end{tabular}

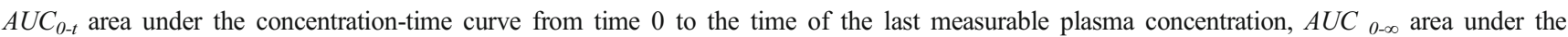
concentration-time curve from time 0 to infinity, $C L$ systemic clearance for aldoxorubicin, $C L / F$ apparent clearance for doxorubicin, $C_{m a x}$ peak plasma concentration of aldoxorubicin after dosing, $N A$ not applicable, $N C$ not calculated, $S D$ standard deviation, $t_{1 / 2}$ apparent half-life of aldoxorubicin, $t_{m a x}$ time to reach $\mathrm{C}_{\max }, V_{d} / F$ apparent volume of distribution of doxorubicin, $V_{s s}$ volume of distribution at steady state of aldoxorubicin

${ }^{a}$ Calculated using doxorubicin-equivalent dose; assumes all aldoxorubicin is hydrolyzed to doxorubicin

${ }^{\mathrm{b}}$ Calculated using aldoxorubicin dose

${ }^{\mathrm{c}}$ The $\mathrm{t}_{\max }$ parameter for doxorubicinol was measured in 4 patients in the $230 \mathrm{mg} / \mathrm{m}^{2}$ cohort

remains bound to albumin via the acid-sensitive linker, and little free doxorubicin is released in the bloodstream.
This is an important point that highlights one major advantage of the covalent bond formed between
Fig. 1 Mean plasma concentration-time profiles of albumin-bound doxorubicin (closed circles), free doxorubicin (open circles), and doxorubicinol (closed triangles) after aldoxorubicin infusion on day 1 of cycle $1(N=18)$

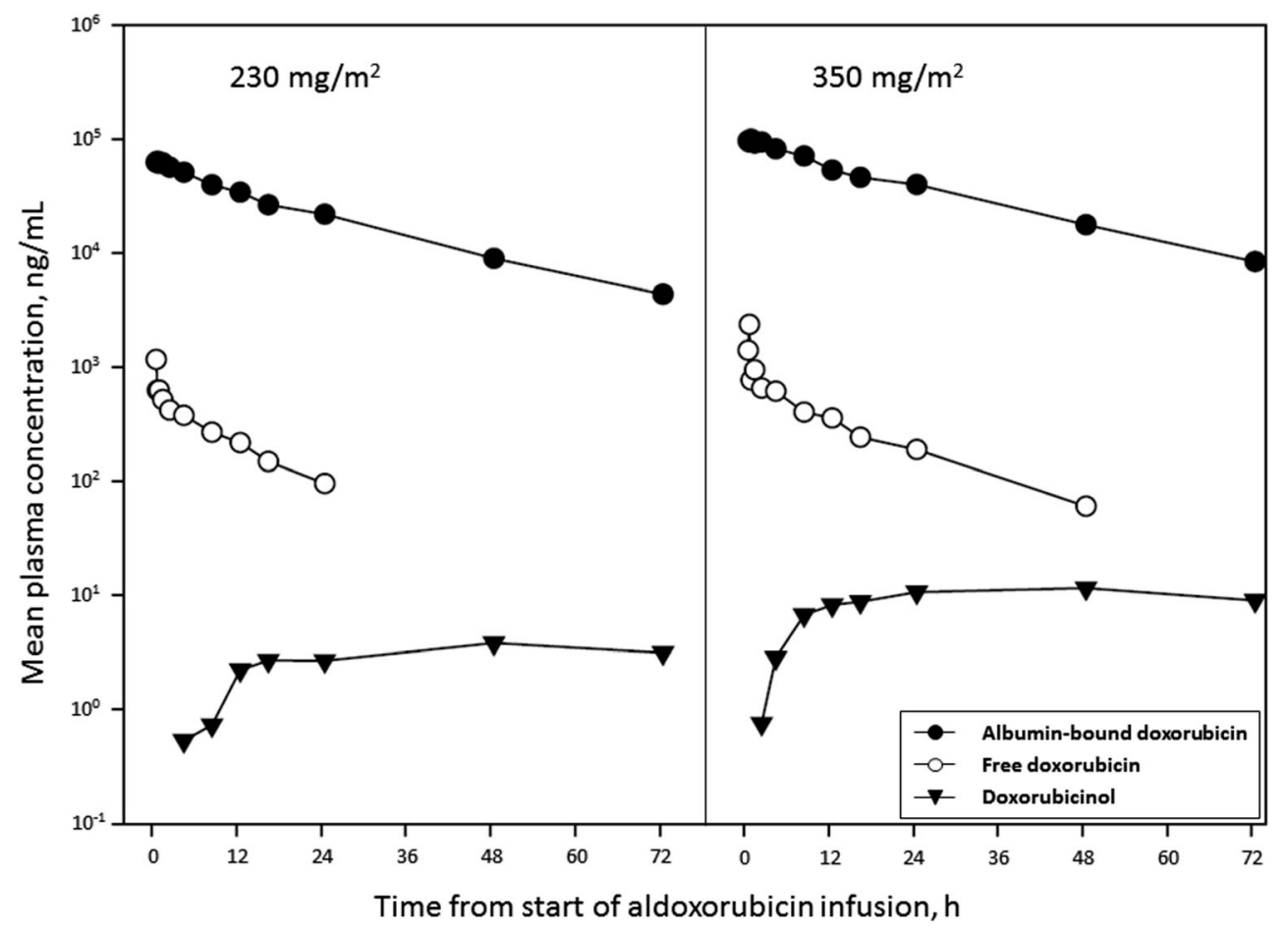



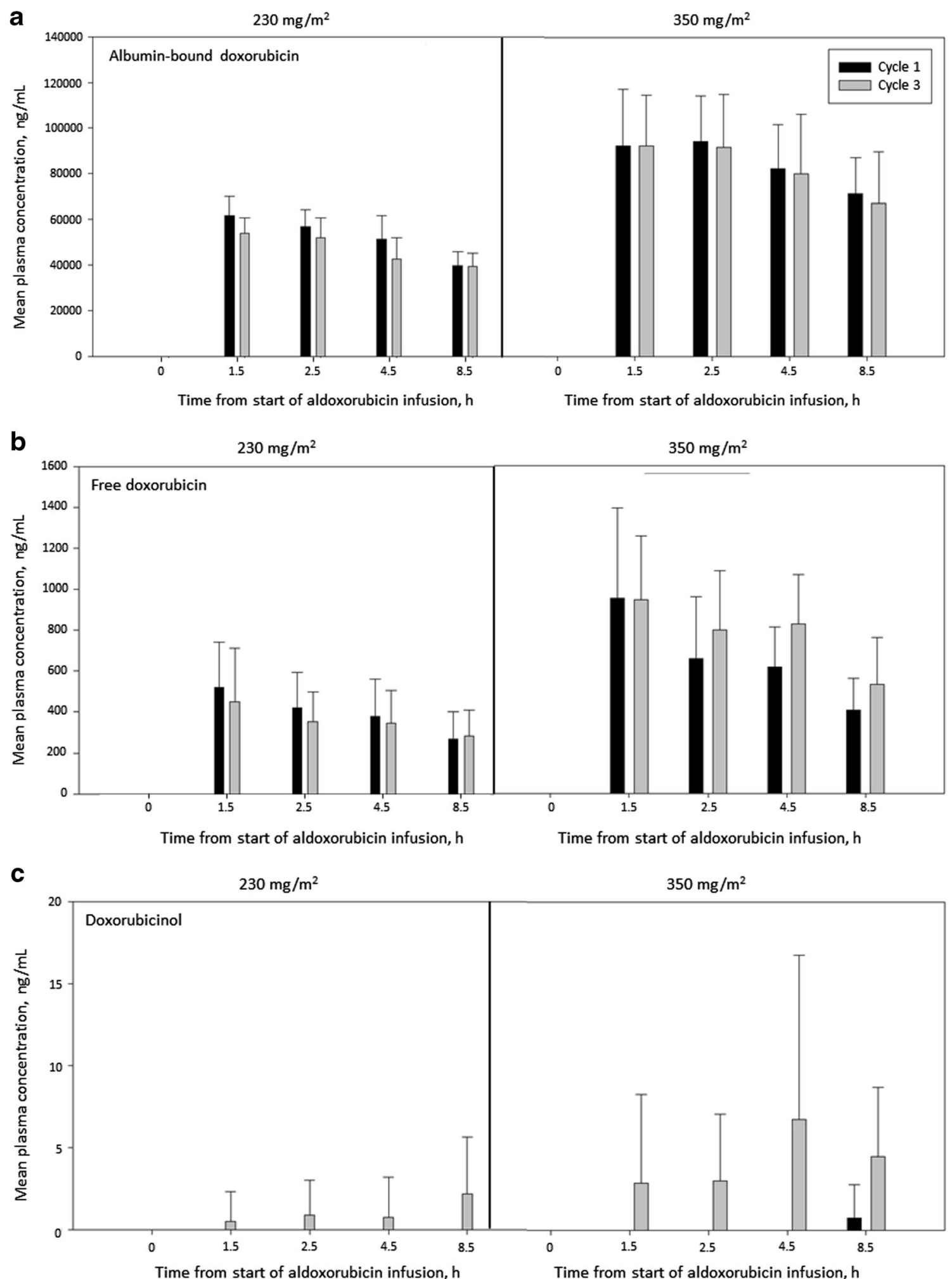

Fig. 2 Comparison of mean plasma concentrations of (a) albumin-bound doxorubicin, (b) free doxorubicin, and (c) doxorubicinol at select time points after infusion of aldoxorubicin on day 1 of cycle $1(N=18$; black bars $)$ and on day 1 of cycle $3(N=11$; gray bars $)$

aldoxorubicin and serum albumin, that release of the drug is conditional upon transport to an acidic environment such as that found at the tumor site.
Our analyses show that very little doxorubicin is excreted in the urine and it is mostly as unmetabolized drug, reinforcing the conclusion that very little doxorubicin is released into the 
Table 3 Urine levels of doxorubicin and doxorubicinol after aldoxorubicin infusion on day 1 of cycle $1(N=18)$

\begin{tabular}{|c|c|c|c|c|}
\hline \multicolumn{5}{|c|}{ Aldoxorubicin $230 \mathrm{mg} / \mathrm{m}^{2}$ dose group $(n=11)$} \\
\hline & \multicolumn{2}{|c|}{ Free doxorubicin, $\mathrm{ng} / \mathrm{mL}$} & \multicolumn{2}{|c|}{ Doxorubicinol, $\mathrm{ng} / \mathrm{mL}$} \\
\hline Time point & Mean (SD) & Median (range) & Mean (SD) & Median (range) \\
\hline $24 \mathrm{~h}$ & $5090(2903)$ & $4220(1250-10,600)$ & $368(233)$ & $363(57-836)$ \\
\hline $48 \mathrm{~h}$ & 3077 (1527) & $2995(1350-5420)$ & $375(225)$ & $341(136-808)$ \\
\hline $72 \mathrm{~h}$ & $1484(700)$ & $1585(591-2360)$ & $336(185)$ & $284(97-625)$ \\
\hline \multicolumn{5}{|c|}{ Aldoxorubicin $350 \mathrm{mg} / \mathrm{m}^{2}$ dose group $(n=7)$} \\
\hline & \multicolumn{2}{|c|}{ Free doxorubicin, $\mathrm{ng} / \mathrm{mL}$} & \multicolumn{2}{|c|}{ Doxorubicinol, ng/mL } \\
\hline Time point & Mean (SD) & Median (range) & Mean (SD) & Median (range) \\
\hline $24 \mathrm{~h}$ & $11514(8876)$ & $7650(3480-27500)$ & $741(410)$ & $747(346-1300)$ \\
\hline $48 \mathrm{~h}$ & $7854(4358)$ & $7470(2170-14500)$ & $1115(783)$ & $928(325-2540)$ \\
\hline $72 \mathrm{~h}$ & 3003 (2407) & $2350(832-8160)$ & $632(471)$ & $506(223-1660)$ \\
\hline
\end{tabular}

$S D$ standard deviation

circulation after administration of aldoxorubicin. Doxorubicinol, which has been implicated in the pathogenesis of cardiomyopathy associated with doxorubicin treatment $[5,6]$, can be detected only in trace amounts. The negligible quantities of this molecule in the circulation may account for the lack of cardiotoxicity observed thus far with aldoxorubicin treatment.

Our thorough pharmacokinetic study provided information that doxorubicin covalently bound to albumin via a $\mathrm{pH}$ sensitive linker is not released into the circulation to any meaningful extent. The safety profile of aldoxorubicin at doxorubicinequivalent doses 2-to 4-fold higher than the standard doxorubicin dose $\left(75 \mathrm{mg} / \mathrm{m}^{2}\right)$ appears favorable, with manageable clinical and hematological toxicities and no evidence of clinically significant acute or cumulative cardiac toxicity even in patients who received over 6 months of therapy. At present, aldoxorubicin is under investigation in a phase 3 randomized controlled study of relapsed metastatic, locally advanced, or unresectable soft tissue sarcoma (ClinicalTrials.gov registry no. NCT02049905), a phase 2 clinical study of recurrent SCLC (ClinicalTrials.gov registry no. NCT02200757), a phase 2 pilot study of glioblastoma (ClinicalTrials.gov registry no. NCT02014844), and a phase 2 pilot study of treatment of HIV-related Kaposi's sarcoma (ClinicalTrials.gov registry no. NCT02029430). Together with the previous phase 1 experience, our study further supports the planned dosing and schedule of aldoxorubicin for these studies with no limitation for the number of cycles and/or cumulative doses of aldoxorubicin.

Table 4 Summary of adverse events, including cardiac events $(N=18)$

\begin{tabular}{|c|c|c|c|}
\hline & \multicolumn{3}{|c|}{ Aldoxorubicin dose group } \\
\hline & $230 \mathrm{mg} / \mathrm{m}^{2}(n=11)$ & $350 \mathrm{mg} / \mathrm{m}^{2}(n=7)$ & All patients $(N=18)$ \\
\hline Median cycles completed, $\mathrm{n}$ (range) & $3(2-21)$ & $3(1-9)$ & $3(1-21)$ \\
\hline Patients with AEs, n (\%) & $11(100)$ & $7(100)$ & $18(100)$ \\
\hline Total AEs, $\mathrm{n}$ & 165 & 105 & 270 \\
\hline Grade 3 or $4 \mathrm{AEs}^{\mathrm{a}}, \mathrm{n}\left(\%^{\mathrm{b}}\right)$ & $8(4.8)$ & $14(13.3)$ & $22(8.1)$ \\
\hline Serious AEs ${ }^{\mathrm{a}}, \mathrm{n}\left(\%^{\mathrm{b}}\right)$ & $3(1.8)$ & $3(2.9)$ & $6(2.2)$ \\
\hline Deaths, $\mathrm{n}$ & $2(18.2)$ & $0(0)$ & $2(0.7)$ \\
\hline \multicolumn{4}{|l|}{ Cardiac events, $\mathrm{n}(\%)$} \\
\hline Patients with $>10 \%$ decrease in LVEF & $1(9.1)$ & $0(0)$ & $1(5.6)$ \\
\hline Patients with LVEF $<45 \%$ & $0(0)$ & $0(0)$ & $0(0)$ \\
\hline Patients with $>5 \%$ prolongation of QTc from baseline & $6(54.5)$ & $4(57.1)$ & $10(55.6)$ \\
\hline Patients with QTc $\geq 500 \mathrm{~ms}$ & $1(9.1)$ & $0(0)$ & $1(5.6)$ \\
\hline
\end{tabular}

$A E$ adverse event, $L V E F$ left ventricular ejection fraction

${ }^{a}$ Does not include deaths

${ }^{\mathrm{b}}$ Percentage of total AEs 
Acknowledgments The authors thank Anna Lau, PhD, and Patricia Segarini, $\mathrm{PhD}$, of Percolation Communications LLC for providing editorial support, and CytRx Corporation for providing financial support of manuscript development.

Funding/support Funding for the study described in this report was provided by CytRx Corporation.

Conflict of interest The authors disclose the following financial relationships that may be viewed as potential conflicts of interest: MMM, RBN, EMW, and ACM report research support from CytRx Corporation. HD, SW, DJL report employment with and stock ownership in CytRx Corporation. BL has no conflict of interest to disclose.

\section{References}

1. Doxorubicin hydrochloride [prescribing information] (2010) Bedford, $\mathrm{OH}$ : Bedford Laboratories

2. National Cancer Institute (2013) Cancer drug information: Doxorubicin hydrochloride. http://www.cancer.gov/cancertopics/ druginfo/doxorubicinhydrochloride/print. Accessed 29 September 2014.

3. Lefrak EA, Pitha J, Rosenheim S, Gottlieb JA (1973) A clinicopathologic analysis of adriamycin cardiotoxicity. Cancer 32 : 302-314

4. Von Hoff DD, Layard MW, Basa P, Davis HL Jr, Von Hoff AL, Rozencweig M, Muggia FM (1979) Risk factors for doxorubicin-induced congestive heart failure. Ann Intern Med 91:710-717

5. Boucek RJ Jr, Olson RD, Brenner DE, Ogunbunmi EM, Inui M, Fleischer S (1987) The major metabolite of doxorubicin is a potent inhibitor of membrane-associated ion pumps. a correlative study of cardiac muscle with isolated membrane fractions. J Biol Chem 262: 15851-15856

6. Del Tacca M, Danesi R, Ducci M, Bernardini C, Romanini A (1985) Might adriamycinol contribute to adriamycininduced cardiotoxicity? Pharmacol Res Commun 17:10731084

7. Kratz F, Warnecke A, Scheuermann K, Stockmar C, Schwab J, Lazar P, Druckes P, Esser N, Drevs J, Rognan D, Bissantz C et al (2002) Probing the cysteine-34 position of endogenous serum albumin with thiol-binding doxorubicin derivatives. improved efficacy of an acidsensitive doxorubicin derivative with specific albumin-binding properties compared to that of the parent compound. J Med Chem 45: $5523-5533$

8. Maeda H, Wu J, Sawa T, Matsumura Y, Hori K (2000) Tumor vascular permeability and the EPR effect in macromolecular therapeutics: a review. J Control Release 65:271-284

9. Unger C, Haring B, Medinger M, Drevs J, Steinbild S, Kratz F, Mross K (2007) Phase I and pharmacokinetic study of the (6maleimidocaproyl)hydrazone derivative of doxorubicin. Clin Cancer Res 13:4858-4866

10. Smith TJ, Khatcheressian J, Lyman GH, Ozer H, Armitage JO, Balducci L, Bennett CL, Cantor SB, Crawford J, Cross SJ, Demetri $\mathrm{G}$ et al (2006) 2006 update of recommendations for the use of white blood cell growth factors: an evidence-based clinical practice guideline. J Clin Oncol 24:3187-3205 